\title{
3 Research Square \\ Identifying longitudinal child growth curve pattern using Functional Principal Component Analysis from birth cohort study in South India
}

\section{Reka Karuppusami}

Christian Medical College and Hospital, Vellore

Antonisamy Belavendra ( $\sim$ b.antonisamy@gmail.com )

Christian Medical College and Hospital, Vellore

Prasanna S. Premkumar

Christian Medical College and Hospital, Vellore

\section{Research Article}

Keywords: Cohort, Child growth, Functional Principal Component Analysis, Longitudinal, Urban Slums

Posted Date: February 23rd, 2021

DOI: https://doi.org/10.21203/rs.3.rs-225326/v1

License: (c) (i) This work is licensed under a Creative Commons Attribution 4.0 International License.

Read Full License 


\section{Abstract}

Background: Human growth studies has long been of interest to researchers and health authorities. Predominantly, the study of physical growth in children is a challenging and complex issue. The goal of a variety of studies from across the world is to develop overall health and well-being in children. It is therefore important that we need to identify an accurate and reliable approach for characterising growth trajectories to distinguish between children who have healthy growth and those growth is poor. Many statistical approaches are available to assess the longitudinal growth data and which are difficult to recognize the pattern. The purpose of this study is to identify the longitudinal child growth trajectory pattern and factors association on the growth function using an advanced statistical technique.

Methods: This longitudinal birth cohort study $(n=290)$ was conducted in three nearby urban slums communities in Vellore, South India. Pregnant women were identified during a survey conducted in 2002 and infants were recruited from birth between the period of March 2002 and August 2003 following written informed consent from the mother. Growth outcomes of height and weight measurements were recorded for each child continuously in first 36 months. Functional Principal Component Analysis was used to classify the longitudinal child growth trajectory pattern. Functional linear model was used to assess the factors association with the growth functions.

Results: We have obtained four functional principal components explained by $86.5 \%, 3.9 \%, 3.1 \%$ and $2.2 \%$ of the variation respectively for the height functions. $38 \%$ of the children's had poor growth trajectories in height. Similarly, we have obtained three functional principal components explained $76.2 \%$, $8.8 \%$, and $4.7 \%$ respectively for the weight functions. $44 \%$ of the children's had poor growth in their weight trajectories. The study shows that gender, socio-economic status, parent's education, breast feeding, and gravida are associated and, influence the growth pattern in children.

Conclusions: The advanced FPC approach deals with subjects' dynamics of growth and not with specific values at given times. FPCA may be a better alternative approach in the sense of both dimension reduction and pattern detection. FPCA may be used to offer greater insight for classification.

\section{Background}

The study of human growth has long been of interest to researchers and health related authorities. In the last decade, human growth has been widely studied due to its association with the socio economic status [1]. Especially, the study of physical growth in children or infants is an interesting and challenging and which depends on many factors such as genetic, malnutrition, physiological and socio-economic factors [2-4]. Normal growth is the greatest indicator of children's well-being and provides an accurate marker of inequalities in human development. This is terribly reflected in the millions of children worldwide who not only fail to achieve their normal growth potential because of health conditions and inadequate care and nutrition. Children with poor growth will permanently damage the physical and cognitive development which is irreversible [5]. 
Stunting often goes unrecognized in societies where short stature is so common that it is considered normal. The difficulty in visually identifying stunted or poor growth children and the lack of routine assessment of normal growth in primary health care services explain why it has taken so long to identify the magnitude of this hidden scourge. Malnutrition among below five year children is a major serious public health problem especially in India, although substantial heterogeneity exists between the states for the various malnutrition indicators and their trends over time. Malnutrition is a major contributor to disease burden, with more than half of global deaths in children younger than 5 years of age attributable to under nutrition, the vast majority of which are in low-income and middle-income countries, including India [6-8]. High amount of malnutrition experienced by children living in urban slum dwellers and similar settings may harmfully impact their health development of physical characteristics such as height or weight. The research interest of this study is to characterize individual growth trajectories, therefore, we have considered the Functional Principal Component analysis (FPCA), a multivariate approach in determining and classifying the growth trajectories from a longitudinal birth cohort study. Functional linear model was applied to assess the association.

\section{Methods}

\section{Birth cohort study}

The design of the study has been reported earlier [9-11]. Longitudinal birth cohort study was conducted in three neighbouring urban slums in Vellore measuring $2.2 \mathrm{sq} . \mathrm{km}$ with a population density of approximately 17,000 per sq.km, South India. The data were collected from these three slums "Kaspa, Ramnaickanpalayam and Chinnallapuram"where the environment is really poor such as open drains, without water and toilets, without secure tenancy, overcrowded clustered houses with many rubbish dumps. The common occupation in the study area is the manual production of tobacco based beedi products for a daily wage. Pregnant women were identified during a survey conducted in 2002 and their infants were recruited from birth between March 2002 and August 2003 following written informed consent from the mother. Children born between March 2002 and August 2003 were followed until their third birthday. The last child was followed up in August 2006. This study has been approved by the Institutional Review Board and ethics committee of Christian Medical College and Hospital. In this study, 290 children were included (Fig.1). Growth outcome at birth was obtained from delivery records available at the first home visit. For each child, the growth outcome at birth were obtained from one month of age in a study-run clinic. Subsequently, height and weight were measured monthly until 36 months by field workers at the study clinic using single measurements. Recumbent length was measured using a standard infantometer and subsequently using a stadiometer, both to the nearest millimetre. Weight was measured using a Salter weighing scale to the nearest 100 grams. Due to missing in follow up outcome of height and weight, we have considered 36 months (3 years) data for the analysis.

\section{Study Variables}


Baseline study characteristics of interest included were gender, height $(\mathrm{cm})$, weight $(\mathrm{kg})$, baby in ICU or not, abortion (yes, no) , mode of delivery (suction, forceps , caesarean ,vaginal) , socio economic status (low, middle, high), gravida $(1,2,3,>3)$, highest education of household (no formal education , Primary school (1-5 years) , Middle school (6-8 years) , High school (9-10 years) , Higher secondary / College/ Polytechnic / Professional ( $>10$ years)), and duration of exclusive breast feeding ( $<3$ months,$\geq 3$ months).

\section{Statistical Methods}

For demographic and other characteristics, data was presented as mean and standard deviation (SD) for normally distributed variables, and as frequency (percentage) for categorical variables. There were few values missing in the follow-up visits of the growth outcomes. Using the Last Observation Carry Forward (LOCF) method of imputation, the data was considered as complete dense data. To handle and analyse the large amount of constantly measured growth data, Functional Data Analysis (FDA) framework was used [12-18].

\section{Smoothing, outlying function and FPCA}

To construct the child growth outcome trajectories into functions, we have applied B-spline system. To construct the basis function, number of order, knots and range were chosen. Using these information along with the number of basis then the $B$ spline basis was generated. The longitudinal child growth trajectories was converted into functions using the B-spline basis with smoothing parameter $(\lambda)$ and which is chosen by the generalized cross-validation (GCV) technique. A B splines-based smoother is used because its simplicity and flexibility for data. $[12,14-18]$. Outlier detection visualizing tools such as Functional version of Box plot and outliergram were used to identify an abnormal function in both outcomes [17-20]. There are two types of variability in the functions: (i) amplitude variation and (ii) phase variation. The amplitude variation deals with the differences in height between the functions. The phase variation deals with the differences in timing of important features between the functions. The registration technique was carried out to improve the curve misalignment $[16,17,21,22]$.

The advanced statistical procedure of Functional Principal Component Analysis was used to extract the information from functional data to identify the different pattern of the child growth function and further functional linear model was used to assess the association between factors and trajectories $[13,15,16$, 18, 23-27]. The statistical analysis was performed using R studio version 3.6.1.

\section{Results}

\section{Sociodemographic characteristics}

The demographic characteristics of the study sample are detailed in the Table 1. In this study, male and female was almost equally distributed as $49.3 \%$ and $50.7 \%$. Baseline mean height $(\mathrm{cm})$ and weight $(\mathrm{kg})$ of the children were 52.75 (SD: 3.28) and 3.65 (SD: 0.71) with 281 children (96.9\%) had never been 
admitted in ICU. $7.2 \%$ of the household did not have their formal education and $62.4 \%$ were from low socio-economic status. About $14 \%$ mothers had abortions more than once and $17.9 \%$ of mothers had gravida more than 3. 91.7\% mothers had normal delivery and exclusive breastfeeding given less than 3 month was $52.7 \%$.

Table 1 Sociodemographic characteristics

\begin{tabular}{|c|c|}
\hline Characteristics & $\begin{array}{c}\mathrm{n}=290 \\
\mathrm{n}(\%)\end{array}$ \\
\hline Height (cm), mean (SD) & $52.75(3.28)$ \\
\hline Weight (kg), mean (SD) & $3.65(0.71)$ \\
\hline \multicolumn{2}{|l|}{ Gender } \\
\hline Male & $143(49.31)$ \\
\hline Female & 147 (50.69) \\
\hline \multicolumn{2}{|l|}{ Baby in ICU } \\
\hline Yes & $9(3.10)$ \\
\hline No & $281(96.90)$ \\
\hline \multicolumn{2}{|l|}{ Abortion } \\
\hline Yes\# & $40(13.79)$ \\
\hline No & $250(86.21)$ \\
\hline \multicolumn{2}{|l|}{ Mode of delivery } \\
\hline Suction or Forceps or Ceasarean & $24(8.28)$ \\
\hline Vaginal & $266(91.72)$ \\
\hline \multicolumn{2}{|l|}{ Socio Economic status } \\
\hline Low & $181(62.41)$ \\
\hline Moderate/High & $109(37.59)$ \\
\hline \multicolumn{2}{|l|}{ Gravida } \\
\hline 1 & $76(26.21)$ \\
\hline 2 & $93(32.07)$ \\
\hline 3 & $69(23.79)$ \\
\hline More than 3* & $52(17.93)$ \\
\hline \multicolumn{2}{|l|}{ Highest Education of Household } \\
\hline Illiterate & $21(7.24)$ \\
\hline Primary & $71(24.48)$ \\
\hline Middle & $83(28.62)$ \\
\hline High & $79(27.25)$ \\
\hline Higher secondary/College/Polytechnic/Professional & $36(12.41)$ \\
\hline $\begin{array}{l}\text { Duration of exclusive breast feeding } \\
<3 \text { months } \\
\geq 3 \text { months }\end{array}$ & $\begin{array}{l}153(52.76) \\
137(47.24)\end{array}$ \\
\hline
\end{tabular}

* More than 3 means ">3 $(4,5,6,7,8)$ " ; \# Abortion(Yes) : 1,2,3

Considering the generated B spline basis, smoothing parameter and second order of penalization, the functions were generated for growth outcomes. The Functional Box plot is given in Fig. 2. It was plotted as $\mathrm{x}$ axis will be taken as age (months) and $\mathrm{y}$ axis will be taken as growth parameter values. Besides the $50 \%$ central region, the $25 \%$ and $75 \%$ central regions were provided as well. It is important to note that the box, the whiskers, and the median can reveal useful information about a functional dataset by looking at 
their size, position, length, and even the shape of the box or the central tendency of median function. In Fig. 3 and 4, there are two measures named Modified Epigraph Index and Modified Band Depth, using these two in $\mathrm{x}$ and $\mathrm{y}$ axis the plots were generated as outliergram for height and weight functions. These two measures provide an idea of how central a function is with respect to a set of functions. A Shape outlier function was noted and confirmed as abnormal function by these two methods and the abnormal function is excluded from the weight functions. There was no magnitude outlier in the functional data.

\section{Functional Principal Component Analysis}

Child growth data contains two main time-varying traits; height, and weight. We have obtained patterns of variation in the growth outcomes by using FPCA. We have obtained the first four FPC related to the height functions and the plot is given in Fig. 5. The first, second, third and fourth FPCs explained $86.5 \%, 3.9 \%$, $3.1 \%$ and $2.2 \%$ of the variation respectively. $90.4 \%$ of the variability being explained by the first two FPC and $95.7 \%$ of the variability was explained by the first 4 FPC. Except the first Eigen function, remaining all are less important. FPC of height function explains that, component 1 accounts for higher deviation from mean for first 12 months, component 2 and 3 are in contrast to component 1 because the deviation occurs after 30 months. Component 4 accounts less deviation before 10 months and after 32 months. These four subgroups correspond to different height patterns, which can be labelled as "poor growth", "general or normal growth", "catch up" and "growth acceleration".

We have obtained the first three FPC related to the weight functions and the plot is given in Fig. 6. The first, second and third FPCs explained $76.2 \%, 8.8 \%$ and $4.7 \%$ of the variation respectively. First two FPCs accounted totally $85 \%$ of the variability and $90 \%$ of the variability was explained by the first 3 FPCs. Component 1 accounts for higher deviation from mean for first 12 months, component 2 is in contrast to component 1 because the deviation occurs after 30 month and overall component 3 accounts less deviation from the mean. These three subgroups correspond to different weight pattern, which can be labelled as "poor growth", "general or normal growth" and "growth acceleration". The Eigen plots for height and weight functions are given in Fig. 7. Majority 38\% (111/290) of the children had poor growth in height. Majority 44\% (128/289) of the children had poor growth in their weight function.

\section{Functional Responses and an Analysis of Variance}

Further an interest was to study what are the factors affecting the growth functions. Functional linear model was used to assess the association between growth function and factors such as gender, socio economic status, duration of breast feeding, gravida, and highest education of house hold. The regression coefficient plot with confidence interval are given in the additional files Fig. 1-10. The study results are given below for the height and weight functions: (i) Male children had growth increments on height and weight function during the first 10 months and 6 months respectively. (ii) Low socio-economic status had shown a poor growth after 6 months on height function and for weight after 3 months compared to children belonging to middle and high socio-economic status. (iii) Children who did not have exclusively breast feeding for more than 3 months are observed to be in poor growth category on height and weight function. (iv) Children born to the parents who are illiterate and primary education had poor 
growth on height and weight function. (v) Children born to the women with higher order of gravida ( $\geq 3$ ) had poor growth on height and weight function.

\section{Discussion}

In public health and environmental research, repeated measures are occasionally obtained at rapid frequencies over longer period of time. In this scenario, using the conventional technique to analyse large amount of data will be difficult. Functional methods provide an alternative flexible approach to common parametric models for analysing panel data and are computationally efficient and easy to implement. This study outlines a modern statistical framework for handling the data, identify the functional patterns inferred from sampled longitudinal child growth data and to study association.

The pattern from the FPCA gives a direct biological interpretation and offers a visual tool to assess the main directions in the functional data. The FPCA approach were shown to be providing a better estimate compared to other conventional methods to handle longitudinal data in biomedical applications $[1,2,14,27-29]$ and characterise trajectories in order to classify the pattern in child growth study [29] and various field of studies [15-17, 22, 24, 25, 27, 30-32]. In the present study, total variation was explained $\geq 90 \%$ for height and weight respectively. In literature review, application of FPC analysis are reported more than $80 \%$ of the total variation in multiple studies $[25,29,31,32]$.

In fact, we know that the growth outcome measurement obtained every month for 3 years exhibits $40 \%$ of the children had poor growth in the slum area, Vellore. Similar finding of high proportion of children had poor growth in their young age were observed in urban slum in India [11, 29, 33-37]. The research finding with the growth data is similar to the existing literature in identifying the subgroup pattern such as "large, catch up, stunting, faltering and average" for the growth outcomes of height, weight, and head circumference. However, existing literature has not reported the percentage of individuals belonging to these subgroups of growth pattern [29]. One of the limitation in the application of this approach to sparse data very challenging and requires numerical computation methods.

There are many factors associated with the poor growth of children's such as inadequate breastfeeding, parent's socio economic status, family environment, and poverty. In this study, relating the more time points with a functional model will provide a complete and accurate figure as to how the study factors individually affect growth functions. The factors such as gender, socio economic status, breast feeding , education, and gravida are important and shown to be associated with growth outcomes [38-42]. There are many steps will be followed to make the information from the curves, but fewer options only available for developing inferences concerning predictor-outcome relationships, in hypothesis-testing of medical studies. The functional regression coefficient will be gained through figure from the modelling of functional regression, especially in the functional outcome and covariates. This model is still needed to develop more and we can consider this as a limitation. For functional inference, the coefficient plots are produced to each level of factors to understand the category nature over time in terms of function but the theoretical foundations for this area have not yet been developed. 


\section{Conclusion}

Longitudinal studies plays a vital role to recognize the growth pattern of children. In this study, we have used FPCA methodology for the child growth data and the growth FPC was obtained with biological interpretation. FPCA provides a useful methodology for the purpose of analysing growth outcome trends because it deals with subjects' dynamics of growth and not with specific values at given times. Using this technique, we identified growth trajectories in order to discriminate the children who have normal growth and who have poor growth. Based on the first 3 years of child growth trajectories, we have found that majority of the children are comes under the greater risk of poor growth pattern among urban slum dwellers in Vellore, India. Occurrence of poor growth in young children will continue in the rest of the following months and will affect the child growth in later development stages. Our study using FPCA for identifying the poor growth pattern is also supporting findings from previous studies [34, 43-45] that in order to make the policy decision in the government level to prevent the poor growth in future. Functional outcome linear regression model also useful to assess the factors association with long-term growth functions. The proposed regression in the research work was used to address an extensive class of problems due to high-dimensional longitudinal data.

\section{Abbreviations}

FDA : Functional Data Analysis ; FPC : Functional Principal Component ; FPCA : Functional Principal Component Analysis ; GCV : generalized cross-validation ; ICU : Intensive Care Unit ; IRB : Institutional Review Board ; LOCF: Last Observation Carry Forward ; SD : Standard Deviation.

\section{Declarations}

\section{Acknowledgements}

The authors would like to thank the field workers of the longitudinal birth cohort study for data collection.

\section{Funding}

This work was supported by the Wellcome Trust Trilateral Initiative for Infectious Diseases, grant no. 063144. The researchers were independent and had no research input from the funding agency.

\section{Availability of data and materials}

The datasets used and/or analysed during the current study are available from the corresponding author on reasonable request.

\section{Authors' contributions}

Conceptualization: RK, BA 
Data curation, Methodology, Formal analysis: RK, BA and PSP

Supervision: BA, PSP

Writing - original draft: RK

Review \& Editing: RK, BA and PSP

\section{Ethics approval and consent to participate}

The study design and procedures were approved by the Institutional Review Board of the Christian Medical College and Hospital, Vellore, India (IRC number: 4544 ; dated 22 Oct 2000). The study was conducted in adherence to the Declaration of Helsinki. The informed consent form was obtained from the mothers of infants expressing their willingness to participate in the study.

\section{Consent for publication}

Not applicable

\section{Competing interests}

The authors declare that they have no competing interests.

\section{References}

1. Anderson $\mathrm{C}$, Hafen R, Sofrygin O, Ryan L, members of the HBGDki Community. Comparing predictive abilities of longitudinal child growth models. Stat Med. 2019;38:3555-70.

2. Anderson C, Xiao L, Checkley W. Using data from multiple studies to develop a child growth correlation matrix. Stat Med. 2019;38:3540-54.

3. Heo J, Krishna A, Perkins JM, Lee H-Y, Lee J-K, Subramanian SV, et al. Community Determinants of Physical Growth and Cognitive Development among Indian Children in Early Childhood: A Multivariate Multilevel Analysis. Int J Environ Res Public Health. 2019;17.

4. Walker SP, Wachs TD, Gardner JM, Lozoff B, Wasserman GA, Pollitt E, et al. Child development: risk factors for adverse outcomes in developing countries. Lancet. 2007;369:145-57.

5. de Onis M, Branca F. Childhood stunting: a global perspective. Matern Child Nutr. 2016;12 Suppl $1: 12-26$.

6. India State-Level Disease Burden Initiative Malnutrition Collaborators. The burden of child and maternal malnutrition and trends in its indicators in the states of India: the Global Burden of Disease Study 1990-2017. Lancet Child Adolesc Health. 2019;3:855-70.

7. GBD 2017 Risk Factor Collaborators. Global, regional, and national comparative risk assessment of 84 behavioural, environmental and occupational, and metabolic risks or clusters of risks for 195 
countries and territories, 1990-2017: a systematic analysis for the Global Burden of Disease Study 2017. Lancet. 2018;392:1923-94.

8. Black RE, Victora CG, Walker SP, Bhutta ZA, Christian P, Onis M de, et al. Maternal and child undernutrition and overweight in low-income and middle-income countries. The Lancet. 2013;382:427-51.

9. Banerjee I, Gladstone BP, Le Fevre AM, Ramani S, Iturriza-Gomara M, Gray JJ, et al. Neonatal Infection with G10P[11] Rotavirus Did Not Confer Protection against Subsequent Rotavirus Infection in a Community Cohort in Vellore, South India. J Infect Dis. 2007;195:625-32.

10. Gladstone BP, Muliyil JP, Jaffar S, Wheeler JG, Le Fevre A, Iturriza-Gomara M, et al. Infant morbidity in an Indian slum birth cohort. Arch Dis Child. 2008;93:479-84.

11. Rehman AM, Gladstone BP, Verghese VP, Muliyil J, Jaffar S, Kang G. Chronic growth faltering amongst a birth cohort of Indian children begins prior to weaning and is highly prevalent at three years of age. Nutr J. 2009;8:44.

12. Reimherr M, Nicolae D. A functional data analysis approach for genetic association studies. Ann Appl Stat. 2014;8:406-29.

13. Escabias M, Valderrama MJ, Aguilera-Morillo MC. Functional Data Analysis in Biometrics and Biostatistics. 2012.

14. Simpkin AJ, Durban M, Lawlor DA, MacDonald-Wallis C, May MT, Metcalfe C, et al. Derivative estimation for longitudinal data analysis: Examining features of blood pressure measured repeatedly during pregnancy. Statistics in Medicine. 2018;37:2836-54.

15. Gubian M, Torreira F, Boves L. Using Functional Data Analysis for investigating multidimensional dynamic phonetic contrasts. Journal of Phonetics. 2015;49:16-40.

16. Hippocampal shape analysis in Alzheimer's disease using functional data analysis - Epifanio - 2014 Statistics in Medicine - Wiley Online Library. https://onlinelibrary.wiley.com/doi/abs/10.1002/sim.5968. Accessed 24 Sep 2020.

17. Sørensen H, Goldsmith J, Sangalli LM. An introduction with medical applications to functional data analysis. Statistics in Medicine. 2013;32:5222-40.

18. Wang J-L, Chiou J-M, Mueller H-G. Review of Functional Data Analysis. arXiv:150705135 [stat]. 2015. http://arxiv.org/abs/1507.05135. Accessed 24 Sep 2020.

19. Dai W, Genton M. Multivariate Functional Data Visualization and Outlier Detection. 2017.

20. Happ C, Greven S, Schmid VJ. The impact of model assumptions in scalar-on-image regression. Stat Med. 2018;37:4298-317.

21. Lee S, Jung S. Combined Analysis of Amplitude and Phase Variations in Functional Data. arXiv:160301775 [stat]. 2017. http://arxiv.org/abs/1603.01775. Accessed 25 Sep 2020.

22. Papayiannis GI, Giakoumakis EA, Manios ED, Moulopoulos SD, Stamatelopoulos KS, Toumanidis ST, et al. A functional supervised learning approach to the study of blood pressure data. Statistics in Medicine. 2018;37:1359-75. 
23. Fang Y, Wang Y. Testing for familial aggregation of functional traits. Stat Med. 2009;28. doi:10.1002/sim.3709.

24. Goldsmith J, Schwartz JE. Variable selection in the functional linear concurrent model. Statistics in Medicine. 2017;36:2237-50.

25. Hosseini-Nasab M, Mirzaei K Z. Functional analysis of glaucoma data. Stat Med. 2014;33:2077102.

26. Sentürk D, Dalrymple LS, Nguyen DV. Functional linear models for zero-inflated count data with application to modeling hospitalizations in patients on dialysis. Stat Med. 2014;33:4825-40.

27. Dean JA, Wong KH, Gay H, Welsh LC, Jones A-B, Schick U, et al. Functional Data Analysis Applied to Modeling of Severe Acute Mucositis and Dysphagia Resulting From Head and Neck Radiation Therapy. International Journal of Radiation Oncology*Biology*Physics. 2016;96:820-31.

28. Dynamic prediction in functional concurrent regression with an application to child growth - PubMed. https://pubmed.ncbi.nlm.nih.gov/29230836/. Accessed 28 Sep 2020.

29. Han K, Hadjipantelis PZ, Wang J-L, Kramer MS, Yang S, Martin RM, et al. Functional principal component analysis for identifying multivariate patterns and archetypes of growth, and their association with long-term cognitive development. PLoS ONE. 2018;13:e0207073.

30. Happ C, Greven S. Multivariate Functional Principal Component Analysis for Data Observed on Different (Dimensional) Domains. Journal of the American Statistical Association. 2018;113:64959.

31. Berrendero JR, Justel A, Svarc M. Principal components for multivariate functional data. Comput Stat Data Anal. 2011;55:2619-34.

32. Górecki T, Krzyśko M, Waszak $Ł$, Wołyński W. Selected statistical methods of data analysis for multivariate functional data. Stat Papers. 2018;59:153-82.

33. Huey SL, Finkelstein JL, Venkatramanan S, Udipi SA, Ghugre P, Thakker V, et al. Prevalence and Correlates of Undernutrition in Young Children Living in Urban Slums of Mumbai, India: A Cross Sectional Study. Front Public Health. 2019;7. doi:10.3389/fpubh.2019.00191.

34. Sahu SK, Kumar SG, Bhat BV, Premarajan KC, Sarkar S, Roy G, et al. Malnutrition among under-five children in India and strategies for control. Journal of Natural Science, Biology, and Medicine. 2015;6:18-23.

35. Patel KA, Langare SD, Naik JD, Rajderkar SS. Gender inequality and bio-social factors in nutritional status among under five children attending anganwadis in an urban slum of a town in Western Maharashtra, India. J Res Med Sci. 2013;18:341-5.

36. Aguayo VM, Nair R, Badgaiyan N, Krishna V. Determinants of stunting and poor linear growth in children under 2 years of age in India: an in-depth analysis of Maharashtra's comprehensive nutrition survey. Matern Child Nutr. 2016;12 Suppl 1:121-40.

37. Jayalakshmi R, Kannan S. The catch-up growth in stunted children: Analysis of first and second India human development survey data. Indian Journal of Community Medicine. 2019;44:199. 
38. Mohammadzadeh A, Farhat A, Amiri R, Esmaeeli H. Effect of Birth Weight and Socioeconomic Status on Children's Growth in Mashhad, Iran. Int J Pediatr. 2010;2010. doi:10.1155/2010/705382.

39. Bocca-Tjeertes IFA, van Buuren S, Bos AF, Kerstjens JM, Ten Vergert EM, Reijneveld SA. Growth of preterm and full-term children aged 0-4 years: integrating median growth and variability in growth charts. J Pediatr. 2012;161:460-465.e1.

40. Gültekin T, Hauspie R, Susanne C, Güleç E. Growth of children living in the outskirts of Ankara: impact of low socio-economic status. Ann Hum Biol. 2006;33:43-54.

41. Baschieri A, Machiyama K, Floyd S, Dube A, Molesworth A, Chihana M, et al. Unintended Childbearing and Child Growth in Northern Malawi. Matern Child Health J. 2017;21:467-74.

42. Velusamy V, Premkumar PS, Kang G. Exclusive breastfeeding practices among mothers in urban slum settlements: pooled analysis from three prospective birth cohort studies in South India. Int Breastfeed J. 2017;12:35.

43. Niklasson A, Engström E, Hård A-L, Wikland KA, Hellström A. Growth in Very Preterm Children: A Longitudinal Study. Pediatric Research. 2003;54:899-905.

44. Black MM, Walker SP, Fernald LCH, Andersen CT, DiGirolamo AM, Lu C, et al. Advancing Early Childhood Development: from Science to Scale 1. Lancet. 2017;389:77-90.

45. Bhutta ZA, Ahmed T, Black RE, Cousens S, Dewey K, Giugliani E, et al. What works? Interventions for maternal and child undernutrition and survival. Lancet. 2008;371:417-40.

\section{Figures}
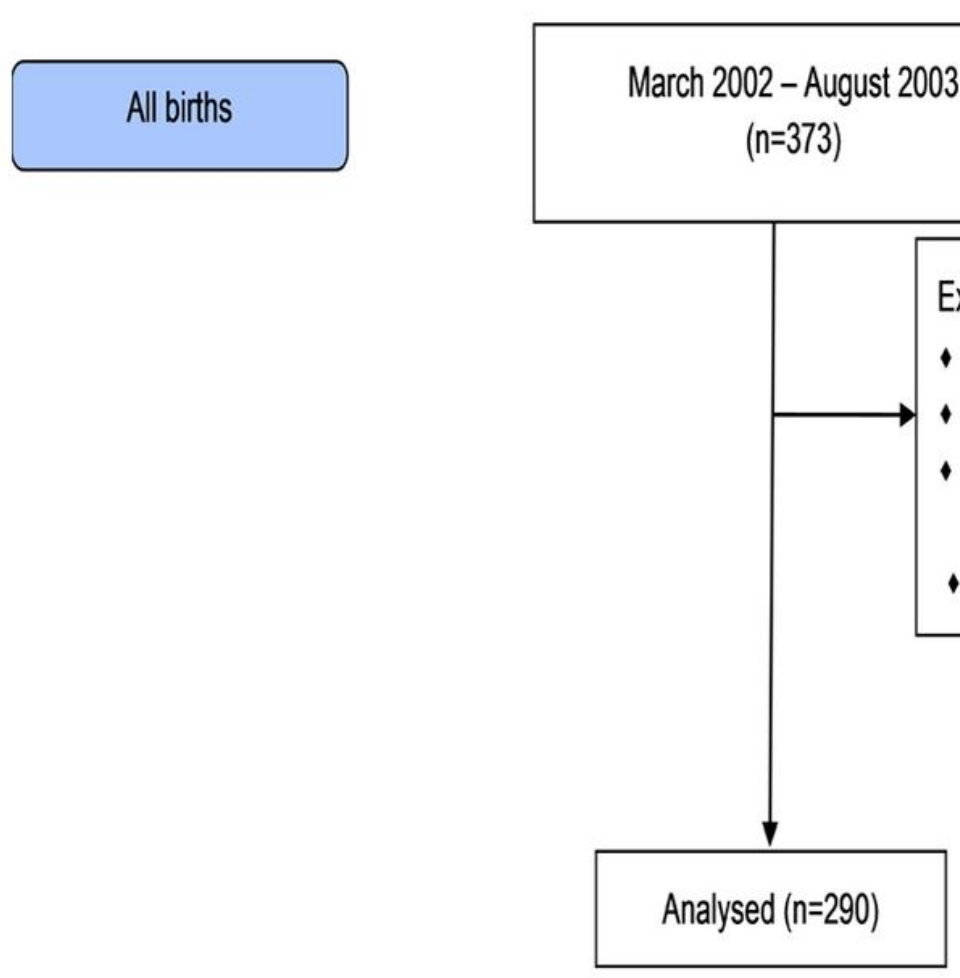

\section{Figure 1}


Flow chart for subjects included in the analysis
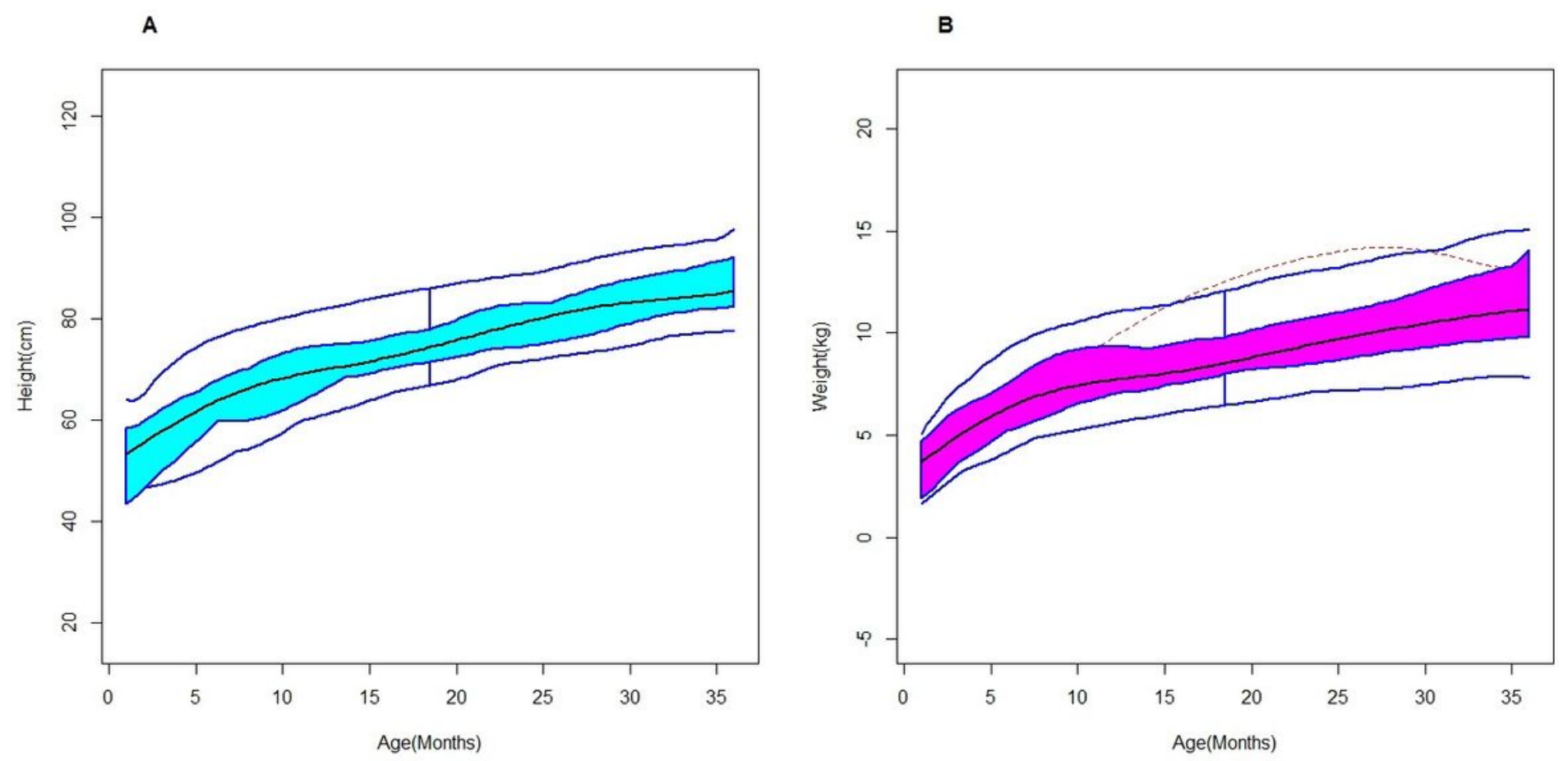

Figure 2

Functional Box plot for height and weight functions
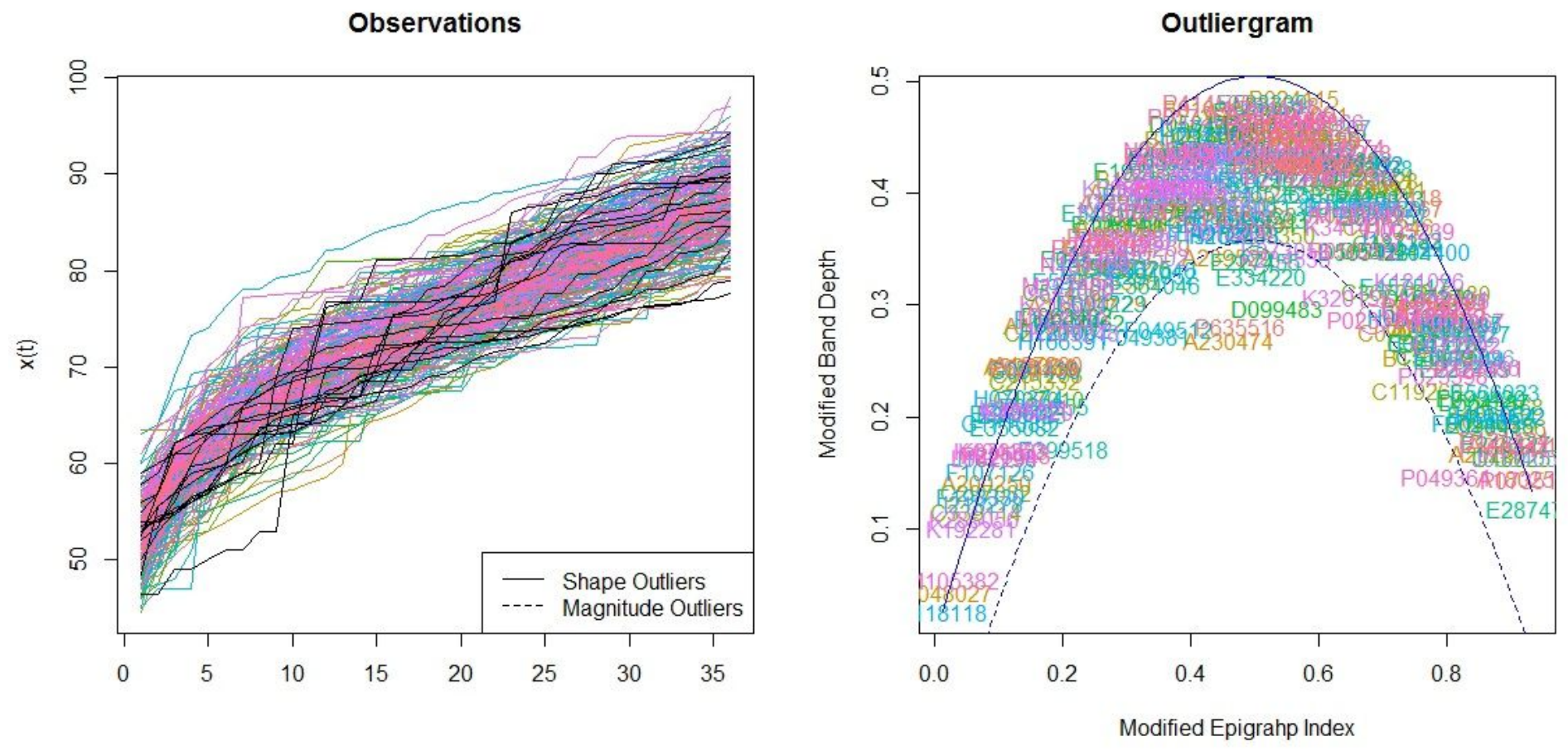

Figure 3

The outliergram plot for height functions 
Observations

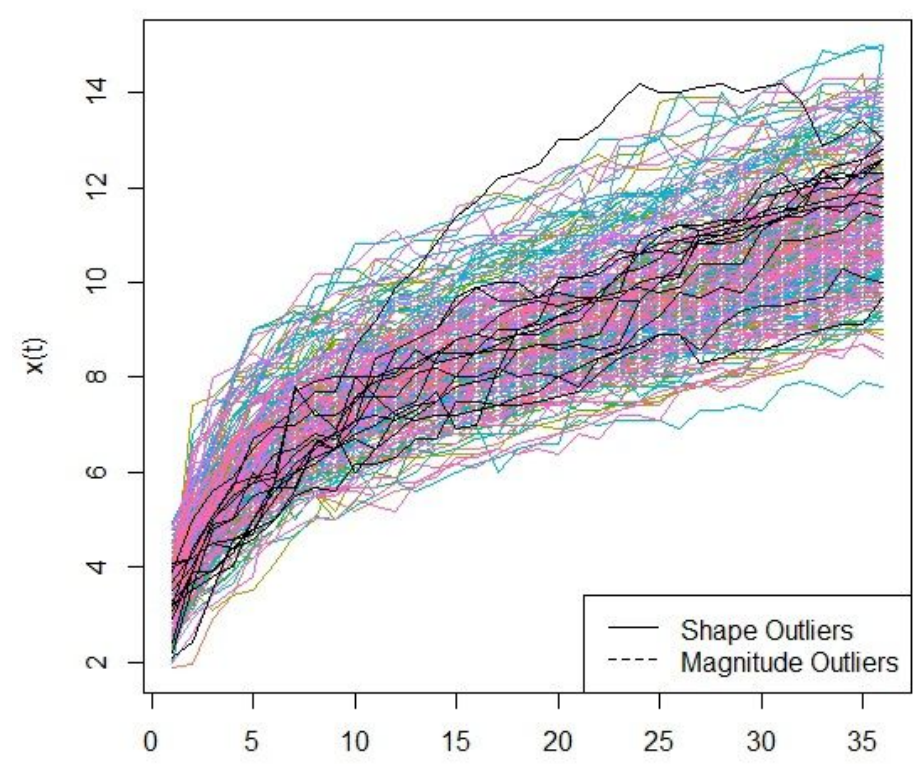

\section{Figure 4}

The outliergram plot for weight functions

PCA function 1 (Percentage of variability 86.5 )

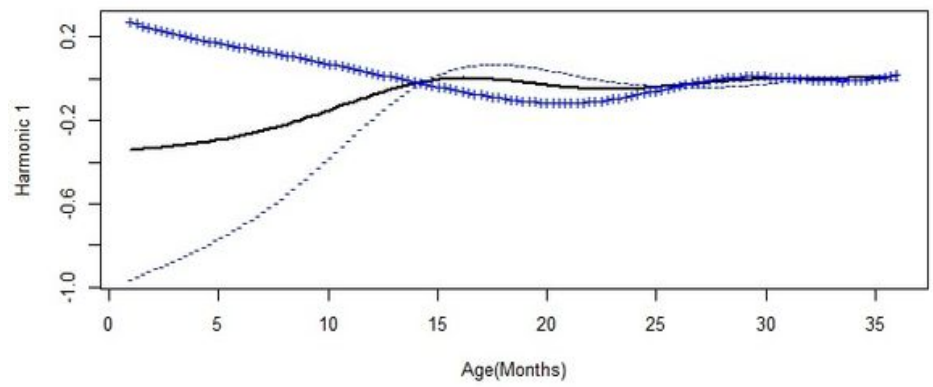

PCA function 3 (Percentage of variability 3.1 )

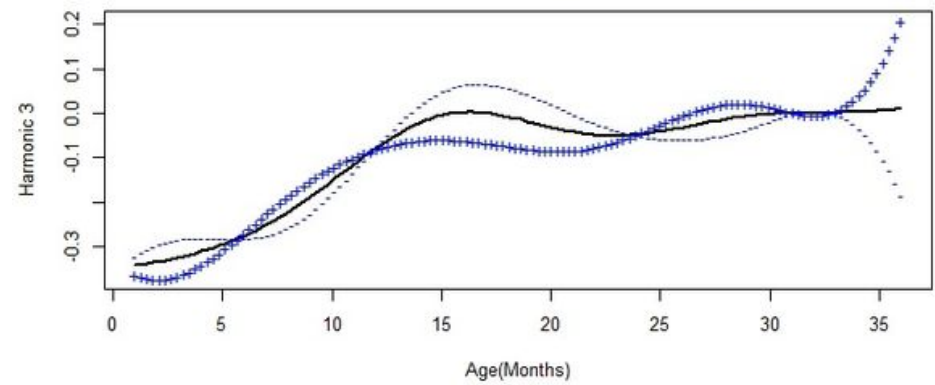

Outliergram
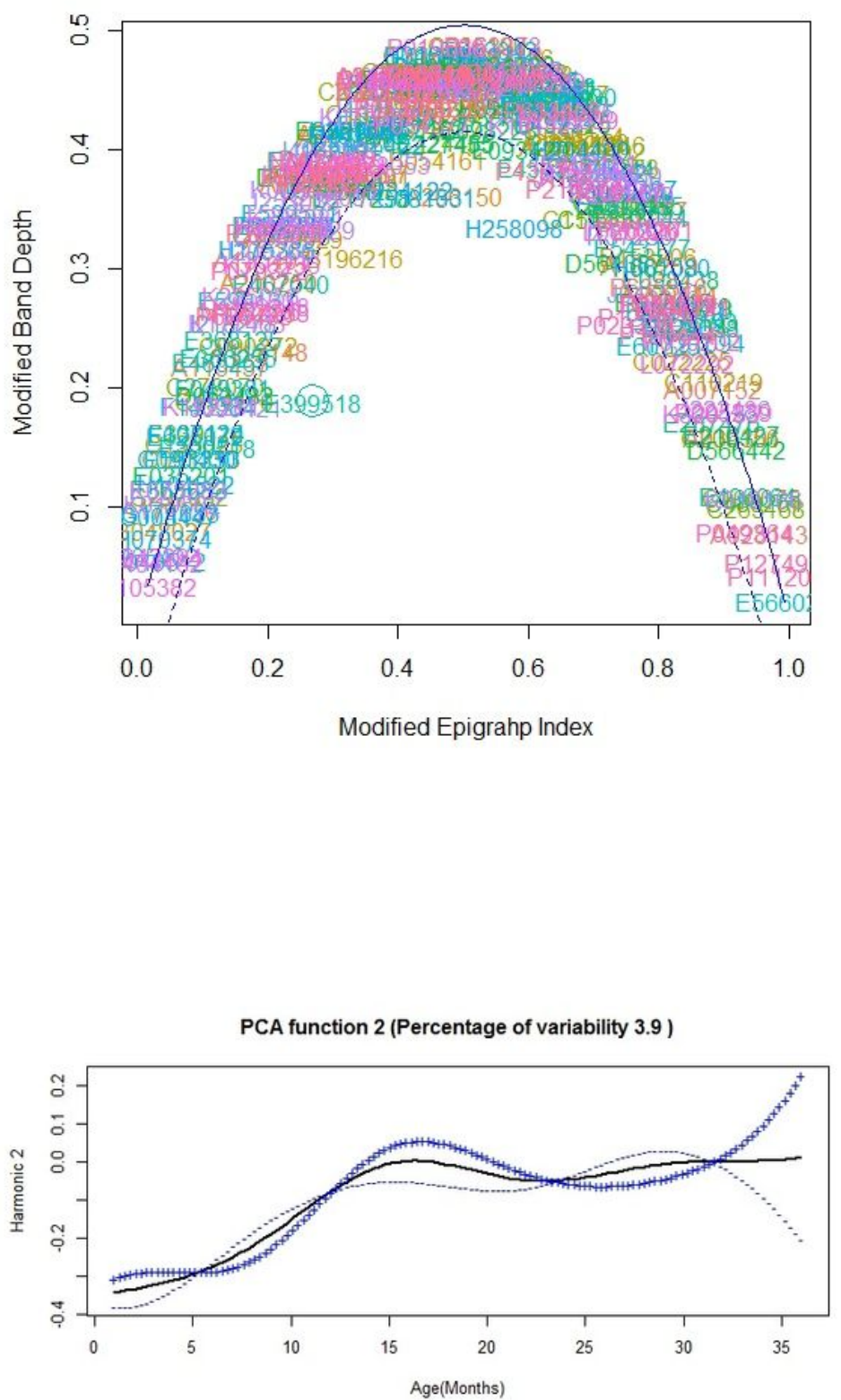

PCA function 4 (Percentage of variability 2.2)

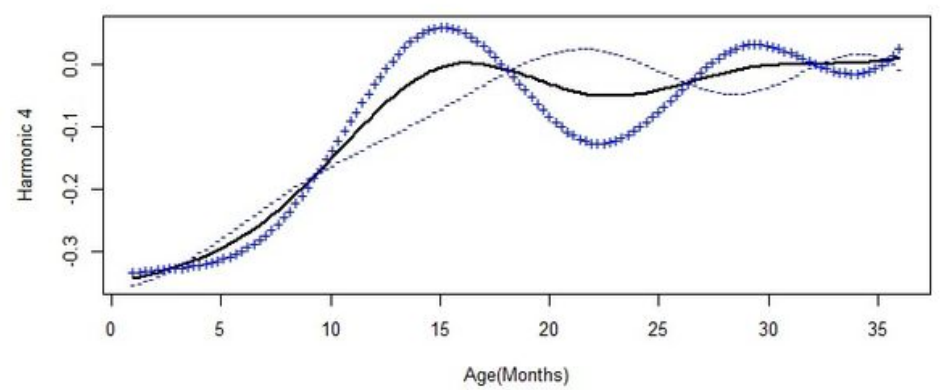

Figure 5

The first four important harmonics, each plot shows the mean function (solid black) +/- small amount of harmonics - aligned height trajectories 

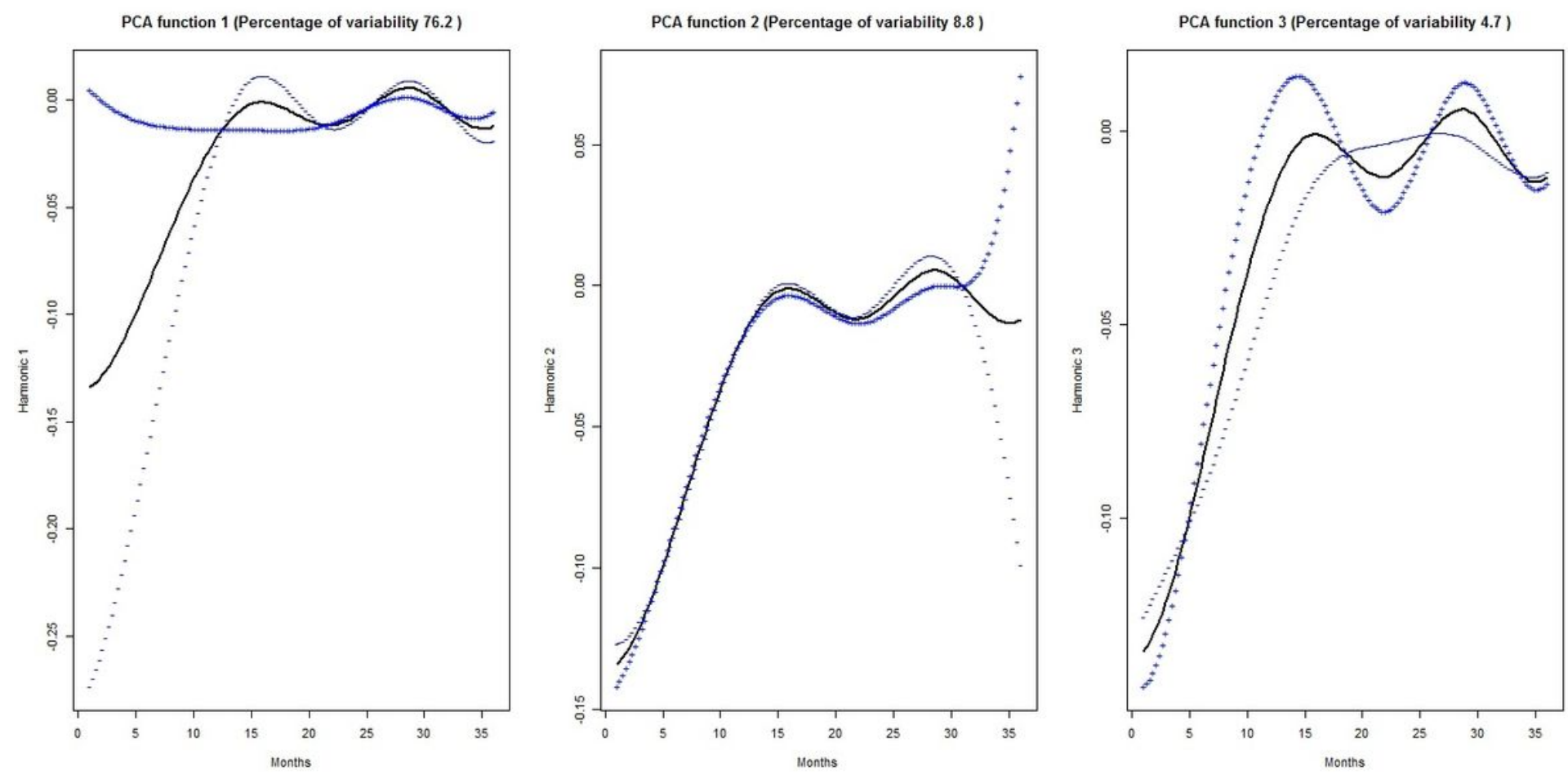

Figure 6

The first three important harmonics, each plot shows the mean function (solid black) +/- small amount of harmonics - aligned weight trajectories
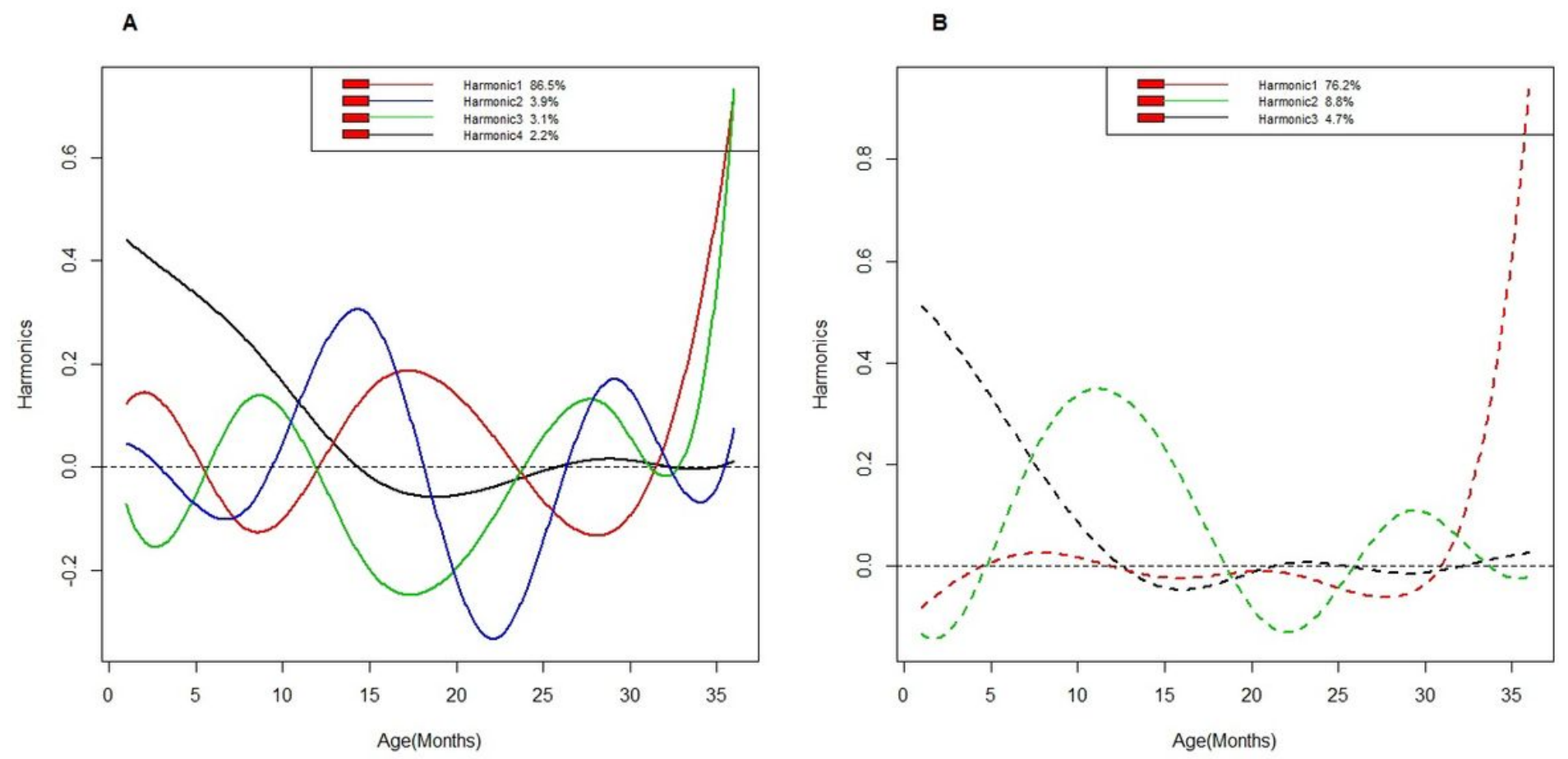

Figure 7

The Eigen plots for height and weight functions 


\section{Supplementary Files}

This is a list of supplementary files associated with this preprint. Click to download.

- Additionalfile1.tif

- Additionalfile2.tif

- Additionalfile3.tif

- Additionalfile4.tif

- Additionalfile5.tif

- Additionalfile6.tif

- Additionalfile7.tif

- Additionalfile8.tif

- Additionalfile9.tif

- Additionalfile10.tif 